\title{
PENGEMBANGAN MEDIA PEMBELAJARAN BERBASIS MULTIMEDIA PADA MATA KULIAH KOMPETENSI PEMBELAJARAN POKOK MATERI KETERAMPILAN DASAR MENGAJAR
}

\author{
Gilang Mawardi, Tuti Iriani', Daryati ${ }^{3}$ \\ 1,2,3 Universitas Negeri Jakarta \\ 1'gilangmawardi12@gmail.com, ${ }^{2}$ tutiiriani@unj.ac.id, ${ }^{3}$ daryati sr@unj.ac.id
}

\author{
Diterima $\quad: 22$ Agustus 2018 \\ Direvisi : 24 Januari 2019 \\ Diterbitkan : 28 Februari 2019 \\ DOI $\quad:$ https://doi.org/10.21009/ipensil.v8i1.8485
}

\begin{abstract}
This research is a type of research and development that aims to produce products in the form of multimedia powerpoint-based learning media in Learning Competency courses. This development research is a Research and Development research method with the 4D (four-D) model. This research is basically done through four main stages, namely define process, design process, develop process, and disseminate process. However, the research only reaches the stage of the development process. This study uses a questionnaire as a tool to test the feasibility of the media through the validation of media experts and material experts. The results of development are multimedia powerpoint-based learning media products. Assessments by material expert lecturers get scores 4,27 categorized as "Very Good". An assessment by a media expert lecturer got a score of 3.31 which was categorized as "Quite Good". The results of the average assessment from material and media experts get the value "3,79" means that multimedia-based learning media is categorized as "Good.".
\end{abstract}

Keywords : learning Media, Multimedia, Learning Competency

\section{Pendahuluan}

Pemanfaatan hasil teknologi dalam pembelajaran sesuai perkembangan zaman dilakukan untuk upaya meningkatkan mutu pendidikan. Peningkatan mutu pendidikan tidak terlepas dari peran seorang tenaga pendidik. Pendidik dituntut mampu memberikan berbagai inovasi menarik dalam pembelajaran, guna mengoptimalkan proses pembelajaran. Menurut Palelupu (2014), diacu dalam Rezeki \& Ishafit (2017: 30) Salah satu inovasi pembelajaran adalah pengembangan media pembelajaran.

Menurut Yudiantara, dkk, (2015: 2) tentang media pembelajaran yaitu: "Media pembelajaran adalah alat yang secara fisik digunakan untuk menyampaikan isi materi pembelajaran yang terdiri dari buku, tape recorder, kaset, video kamera, video recorder, film, slide, foto, gambar, grafik, televisi dan komputer". Sedangkan Menurut Sanjaya (2011: 210) tentang manfaat media pembelajaran yaitu: "Manfaat media pembelajaran adalah memperlancar interaksi antara pendidik dengan peserta didik, memperjelas penyajian materi, menciptakan suasana belajar yang menarik dan interaktif, memberikan pengalaman nyata bagi peserta didik, meningkatkan motivasi belajar peserta didik, mengefisienkan waktu pembelajaran dan lain sebagainya".

Dari pendapat di atas dapat disimpulkan media pembelajaran merupakan segala bentuk yang digunakan untuk membawa pesan-pesan atau informasi yang memiliki manfaat dan tujuan pembelajaran.

Berbagai media pembelajaran dapat mempermudah aktivitas belajar bagi peserta didik, salah satunya adalah media pembelajaran berbasis multimedia. Menurut 
Diah \& Nita (2018: 70) Pembelajaran berbasis multimedia adalah pembelajaran yang menggunakan bantuan komputer atau multimedia dengan memanfaatkan android. Sedangkan menurut Diartono (2008: 159) Pembelajaran dengan multimedia merupakan gabungan dari berbagai macam media yang terintegrasi yang secara bersama-sama menampilkan informasi, pesan, atau isi pelajaran.

Dari pendapat di atas dapat disimpulkan multimedia pembelajaran merupakan berbagai bentuk media yang digunakan untuk menyajikan suatu informasi secara berurutan maupun simultan melalui komputer.

Ada bebrapa program yang dapat membuat multimedia, seperti Powerpoint, Macromedia Flash, 3D Studio Max, Adobe Flash, dan lain sebagainya. Dari software yang ada, Powerpoint dipilih untuk digunakan sebagai media pembelajaran, karena program Powerpoint sudah sangat akrab dengan dunia pendidikan dan menjadi pilihan media pembelajaran yang sering digunakan, oleh karena itu media powerpoint patut dikembangkan agar pembelajaran menarik bagi mahasiswa.

Kelebihan program Powerpoint dapat digunakan untuk membuat media presentasi interaktif dengan kemampuan pengolahan teks, warna, dan gambar, serta animasi yang bisa diolah sendiri sesuai kreativitas penggunanya (Realita, , dkk, 2014). Program Powerpoint juga mudah diakses dan sudah termasuk program yang sudah ada di komputer itu sendiri, jadi tidak perlu di instal programnya terlebih dahulu.

Program studi Pendidikan Vokasional Konstrusksi Bangunan (PVKB) dalam memaksimalkan proses perkuliahan yang baik, para dosen menyediakan cara tersendiri untuk menyajikan sebuah materi perkuliahan, seperti menggunakan media yang cocok untuk menyajikan isi materi perkuliahan. Dari beberapa mata kuliah pada program studi PVKB yang ada, powerpoint menjadi salah satu pilihan dosen untuk dijadikan sebagai media pembelajaran dalam proses perkuliahan. Salah satu mata kuliah yang memakai media powerpoint yaitu Kompetensi Pembelajaran.

Kompetensi Pembelajaran (KP) merupakan salah satu Mata Kuliah Pembelajaran (MKP) pada program studi PVKB. KP terdiri dari $30 \%$ teori dan $70 \%$ praktikum. KP menjadi mata kuliah yang sangat penting, karena bertujuan untuk memberikan pelatihan kemampuan mengajar dan meningkatkan kompetensi dalam mengajar. KP menjadi salah satu MKP yang mendukung persiapan bekal mahasiswa PVKB untuk mengikuti kegiatan Praktikum Keterampilan Mengajar (PKM) di Sekolah Menengah Kejuruan (SMK) sesuai bidang keahlian program studi.

Berbagai usaha dilakukan dalam mempersiapkan mahasiswa untuk mendapatkan ilmu tentang keterampilan dalam mengajar. Selain dengan latihan dalam bentuk microteaching, memberikan teori dan konsep keterampilan dalam mengajar juga diperlukan sebagai tahap awal sebelum melakukan kegiatan Pratik microteaching.

Proses pembelajaran teori dan konsep keterampilan dasar mengajar, selama ini disampaikan melalui media pembelajaran powerpoint, namun materi yang disajikan hanya penjelasan teori dan konsep semata. Penyajian materi juga belum memenuhi konten multimedia seperti video contoh keterampilan mengajar.

Penambahan unsur multimedia di dalam materi keterampilan dasar mengajar sangat berguna bagi mahasiswa, karena dari sisi visual, dengan penambahan video mereka dapat melihat contoh keterampilan mengajar yang sebenarnya, selain itu konten multimedia yang lain seperti animasi, suara dan gambar juga ditambahkan agar pembelajaran lebih menarik.

Penggunaan pembelajaran berbasis multimedia dapat dilakukan secara mandiri dalam pembelajaran yang menuntut aktivitas mahasiswa untuk melakukan, bekerja dan menemukan sendiri pengetahuan yang dipelajari. Media Powerpoint biasanya digunakan dalam sebuah presentasi, akan tetapi program ini memiliki

Pengembangan Media Pembelajaran... - 25 Gilang 
fasilitas-fasilitas untuk membuat multimedia pembelajaran mandiri. Peneliti dapat menambahkan konten multimedia (teks, suara, gambar, video, dan animasi). Slide atau halaman pada powerpoint dirancang khusus dengan dilengkapi tombol-tombol yang akan melibatkan pengguna dalam pengoperasian powerpoint.

Hasil dari analisis kebutuhan media pembelajaran berbasis multimedia pada mata kuliah Kompetensi Pembelajaran yang diperoleh 28 mahasiswa yaitu: (1) Tingkat Ketertarikan mahasiswa terhadap mata kuliah Kompetensi Pembelajaran yaitu masih dalam kategori cukup tertarik dengan respon $71,4 \%$ atau 20 mahasiswa; (2) Tingkat pemahaman mahasiswa terhadap penggunaan media powerpoint yang telah digunakan pada mata kuliah Kompetensi Pembelajaran yaitu masih dalam kategori cukup paham dengan respon $64,3 \%$ atau 18 mahasiswa; (3) kebutuhan akan penambahan tampilan konten untuk powerpoint dengan respon 89,3\% atau 25 mahasiswa; (4) Kebutuhan tampilan konten powerpoint yang dipilih oleh mahasiswa kebanyakan adalah tampilan konten multimedia dengan respon $80 \%$ atau 20 mahasiswa.

Berdasarkan analisis kebutuhan menunjukkan bahwa media powverpoint yang digunakan sampai saat ini masih belum sesuai harapan mahasiswa, karena perlu ada pengembangan dengan penambahan konten terhadap media powerpoint agar menjadi lebih menarik dan dipahami mahasiswa.

Mencermati dari apa yang telah dijabarkan, peneliti tertarik untuk mengetahui lebih lanjut. Oleh karena itu selanjutnya penelitian ini dituangkan dengan judul "Pengembangan Media Pembelajaran Berbasis Multimedia pada Mata Kuliah Kompetensi Pembelajaran Pokok Materi Keterampilan Dasar Mengajar".

\section{Identifikasi Masalah}

Berdasarkan Latar belakang masalah di atas, maka dapat diidentifikasi beberapa masalah sebagai berikut :.
1. Penyajian materi keterampilan dasar mengajar pada powerpoint belum memenuhi konten multimedia seperti video contoh keterampilan mengajar.

2. Tingkat Ketertarikan mahasiswa terhadap mata kuliah Kompetensi Pembelajaran yaitu masih dalam kategori cukup.

3. Tingkat pemahaman mahasiswa terhadap penggunaan media powerpoint yang telah digunakan pada mata kuliah Kompetensi Pembelajaran yaitu masih dalam kategori cukup.

4. Penggunaan media pembelajaran powerpoint yang digunakan sampai saat ini perlu penambahan konten multimedia.

\section{Pembatasan Masalah}

Berdasarkan Latar Belakang di atas, maka dalam penelitian ini permasalahan dibatasi pada:

1. Pengembangan media pembelajaran berbasis multimedia menggunakan aplikasi powerpoint di program studi PVKB Universitas Negeri Jakarta.

2. Materi yang disajikan pada media pembelajaran berbasis multimedia adalah 8 Keterampilan Mengajar.

3. Penelitian ini akan dilakukan pada semester 108, tahun ajaran 2018/2019.

\section{Rumusan Masalah}

Berdasarkan latar belakang masalah, identifikasi masalah, dan pembatasan masalah yang sudah dijabarkan di atas, maka dapat dibuat perumusan masalah penelitian ini yaitu : Bagaimana pengembangan media pembelajaran berbasis multimedia pada mata kuliah Kompetensi Pembelajaran?.

\section{Kegunaan Hasil Penelitian}

Penelitian ini memiliki beberapa kegunaan diantaranya:

\section{Kegunaan Teoretis}




\begin{abstract}
Penelitian ini diharapkan dapat menjadi sumber acuan dalam pengembangan atau penerapan media pembelajaran lebih lanjut. Selain itu juga menjadi nilai tambah untuk ilmu pengetahuan bidang pendidikan.
\end{abstract}

\section{Kegunaan Praktis}

1. Membantu mahasiswa di dalam proses pembelajaran maksimal dengan pengembangan media pembelajaran berbasis multimedia pada mata kuliah Kompetensi Pembelajaran.

2. Memberikan sumbangan ilmu terkait informasi dalam mengembangkan media pembelajaran berbasis multimedia.

3. Sebagai bahan pertimbangan dalam menggunakan media pembelajaran berbasis multimedia pada setiap mata kuliah di Universitas Negeri Jakarta

\section{Tinjauan Pustaka}

\section{Media Pembelajaran}

Menurut Riyana (2012:11), Media Pembelajaran merupakan wadah dari pesan pembelajaran yang ingin disampaikan dengan tujuan untuk mencapai proses pembelajaran. Sedangkan menurut Umam (2017: 401) menyatakan, Media Pembelajaran adalah sarana untuk merangsang pikiran, perhatian dan minat peserta didik dalam belajar.

Berdasarkan pendapat diatas, dapat disimpulkan Media Pembelajaran adalah segala sesuatu yang dapat digunakan untuk menyalurkan pesan-pesan atau informasi yang dapat merangsang pikiran, perhatian, dan minat sehingga tujuan pembelajaran efektif tercapai.

\section{Multimedia}

Menurut Yudiantara, dkk, (2015: 3) Multimedia diartikan sebagai penggunaan beberapa media yang berbeda dalam menyampaikan informasi berbentuk text, audio, grafik, animasi, dan video. Sedangkan menurut Erdisna \& Rahman (2015: 29) berpendapat mengenai multimedia yaitu: "Multimedia merupkan perpaduan antara berbagai media (format file) yang berupa teks, gambar, grafik, sound, animasi, video, interaksi, dan sebagainya yang telah dikemas menjadi file digital (komputerisasi), digunakan untuk menyampaikan pesan kepada publik". Selanjutnya diperkuat lagi oleh Munir (2012: 5) Multimedia dapat diartikan sebagai gabungan dari berbagai media teks, gambar, video dan animasi dalam satu program berbasis komputer yang dapat memfasilitasi komunikasi interaktif.

Berdasarkan beberapa pendapat diatas dapat disimpulkan bahwa multimedia adalah teknologi berbasis komputer atau digital lain yang mengkombinasikan teks, suara, grafik, video, serta animasi dalam sebuah tampilan yang dapat memfasilitasi komunikasi interaktif.

\section{Materi Kompetensi Pembelajaran}

Materi tentang teori dan konsep yang pada perkuliahan Kompetensi Pembelajaran diantaranya: (1) Pengertian kompetensi; (2) 4 kompetensi guru; (3) Konsep belajar 7 mengajar; (4) 8 keterampilan mengajar.

Dari materi Kompetensi Pembelajaran di atas, 8 keterampilan mengajar dipilih untuk dijadikkan sebagai bahan pada media pembelajaran berbasis multimedia yang akan dikembangkan oleh peneliti, karena pada materi tersebut, mempelajari kajian tentang teori dan konsep keterampilan mengajar yang harus dikuasai bagi setiap calon pengajar, khususnya mahasiswa program studi PVKB FT UNJ yang akan mengikuti kegiatan PKM di SMK. Sebelum kegiatan PKM dilaksanakan, mahasiswa wajib lulus pada Mata Kuliah Pendidikan (MKP), salah satunya mata kuliah Kompetensi Pembelajaran.

Berkaitan dengan materi yang disajikan pada media pembelajaran berbasis multimedia, oleh karena itu materi yang disajikan harus dapat menampilkan konten 
multimedia. Materi 8 keterampilan mengajar dapat menyajikan teori, konsep, serta contoh video keterampilan mengajar.

\section{Tujuan Penelitian}

Menghasilkan produk media pembelajan berbasis multimedia pada mata kuliah kompetensi pembelajaran.

\section{Metode Penelitian}

Penelitian ini dilaksanakan di program studi Pendidikan Vokasional Konstruksi Bangunan Universitas Negeri Jakarta. Tahun ajaran 2017/2018.

Penelitian ini mengacu pada model penelitian dan pengembangan 4D (Four-D). Model penelitian ini terdiri atas 4 tahap utama yakni Pendefinifian (define), Perancangan (design), pengembangan (develop), dan penyebaran (disseminate). Berikut bagan alur penelitian dan pengembangan media.

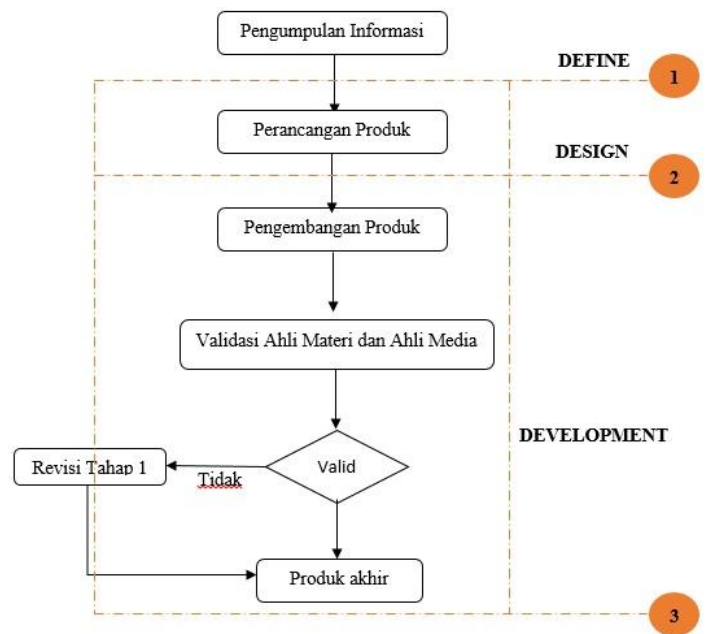

Gambar 1. Alur Pengembangan Media

Berdasarkan gambar di atas, alur pengembangan media yang digunakan peneliti menggunakan model penelitian dan pengembangan 4D, namun langkah penelitian yang digunakan oleh peneliti hanya sebatas sampai tahap pengembangan yaitu menghasilkan produk, karena keterbatasan waktu penelitian yang singkat, penelitian tidak memungkinkan untuk sampai pada tahap pengembangan uji coba mahasiswa dan penyebaran.

Penelitian pengembangan ini menggunakan teknik analisis untuk mengolah data yang diperoleh melalui angket dalam bentuk skor yang diubah menjadi nilai atau kategori dengan acuan tabel yang diadaptasi dari Sukardjo dalam Suartama (2010).

Tabel 1. Kriteria penilaian kelayakan

\begin{tabular}{|l|c|l|}
\hline \multicolumn{1}{|c|}{ Rumus } & $\begin{array}{c}\text { Perhitun } \\
\text { gan }\end{array}$ & $\begin{array}{l}\text { Klasifikasi } \\
\text { Kelayakan }\end{array}$ \\
\hline $\begin{array}{l}\mathrm{X}>\mathrm{Mi}+1,8 \\
\text { Sbi }\end{array}$ & $\mathrm{X}>4,21$ & $\begin{array}{l}\text { Sangat } \\
\text { Baik }\end{array}$ \\
\hline $\begin{array}{l}\mathrm{Mi}+0,6 \text { Sbi }< \\
\mathrm{X} \leq \mathrm{Mi}+1,8 \\
\text { Sbi }\end{array}$ & $\begin{array}{c}3,40<\mathrm{X} \\
\leq 4,21\end{array}$ & Baik \\
\hline $\begin{array}{l}\text { Mi }-0,6 \text { Sbi } \leq \\
\mathrm{X} \leq \mathrm{Mi}+0,6 \\
\text { Sbi }\end{array}$ & $\begin{array}{c}2,60<\mathrm{X} \\
\leq 3,40\end{array}$ & $\begin{array}{l}\text { Cukup } \\
\text { Baik }\end{array}$ \\
\hline $\begin{array}{l}\text { Mi }-1,8 \text { Sbi }< \\
\mathrm{X} \leq \mathrm{Mi}-0,6 \\
\text { Sbi }\end{array}$ & $\begin{array}{c}1,79<\mathrm{X} \\
\leq 2,60\end{array}$ & $\begin{array}{l}\text { Kurang } \\
\text { Baik }\end{array}$ \\
\hline $\begin{array}{l}\mathrm{X} \leq \mathrm{Mi}-1,8 \\
\text { Sbi }\end{array}$ & $\mathrm{X} \leq 1,79$ & $\begin{array}{l}\text { Sangat } \\
\text { Tidak Baik }\end{array}$ \\
\hline \multicolumn{2}{|l|}{} \\
\hline \multicolumn{2}{|l|}{ Sumber: Sukardjo dalam Suartama (2010) } \\
\hline
\end{tabular}

Keterangan:

X : Skor Aktual

Jumlah skor maksimal $\quad: 5$

Jumlah skor minimal $\quad: 1$

Mi (mean ideal) :

$1 / 2 \times$ (jumlah skor maksimal + jumlah skor minimal)

Mi (mean ideal) : 3

Sbi (simpangan baku ideal) :

$1 / 6$ x (jumlah skor maksimal - jumlah skor minimal)

Sbi (simpangan baku ideal) $\quad$ : 0,67

\section{Pembahasan Hasil Penelitian}

Berdasarkan validasi atau penilaian yang sudah dilakukan oleh ahli media dan ahli materi yaitu: (1) Penilaian ahli media diperoleh rata-rata keseluruhan skor 3,31, 
artinya penilaian dari segi media termasuk kategori "Cukup Baik"; (2) Penilaian ahli matei diperoleh rata-rata skor 4,27, artinya penilaian dari segi materi termasuk kategori "Sangat Baik".

Berdasarkan penilaian keseluruhan dari ahli media dan ahli materi diperoleh hasil validasi media pembelajaran berbasis multimedia yaitu penilaian oleh ahli media dan ahli materi diperoleh rata-rata skor 3,79 , artinya media termasuk dalam katergori "Baik" sebagai media pembelajaran pada mata kuliah Kompetensi Pembelajaran.

\section{Hasil Pengembangan Media}

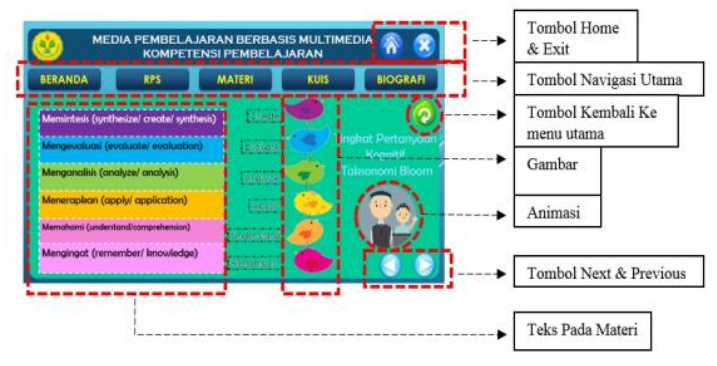

Gambar 2. Hasil Pengembangan Media

Hasil pengembangan media pembelajaran berbasis multimedia terdiri dari teks, suara, gambar, animasi, video, dan dilengkapi dengan tombol-tombol navigasi diantaranya: (1) Tombol home \& Exit, (2) Tombol navigasi utama yaitu: Beranda, RPS, Materi, Kuis, dan Biografi; (3) Tombol kembali ke menu utama; (4) Tombol Next $\&$ Previous

\section{Kualitas Media}

Berdasarkan validasi media yang dilakukan oleh ahli media dan ahli materi, kualitas media pembelajaran berbasis multimedia yang dihasilkan, diihat dari aspek media memperoleh penilaian pada kategori "Cukup Baik". Hal ini dapat dililihat dari media yang dihasilkan masih dalam tahap penyempurnaan sehingga revisi media yang diberikan cukup banyak. Sedangkan dari aspek materi yang disajikan memperoleh penilaian pada kategori
"Sangat Baik". Artinya isi materi yang disajikan sangat cocok untuk media pembelajaran berbasis multimedia. Hasil perolehan keseluruhan dari ahli media dan ahli materi menunjukkan bahwa media pembelajaran berbasis multimedia yang dikembangkan dikategorikan "Baik". Artinya produk yang dihasilkan dapat digunakan untuk pembelajaran.

\section{Kesimpulan}

Berdasarkan hasil penelitian pengembangan media pembelajaran berbasis multimedia dapat disimpulkan bahwa:

1. Hasil yang diperoleh dari penilaian ahli media dan ahli materi menunjukkan bahwa media termasuk dalam katergori "Baik" dengan skor 3,79, artinya produk yang sudah dikembangkan dapat digunakan sebagai media pembelajaran pada mata kuliah Kompetensi Pembelajaran.

2. Hasil media pembelajaran yang dikembangkan sudah memenuhi standar dan konsep multimedia yang digunakan pada program powerpoint, sehingga dapat digunakan untuk pembelajaran di kelas.

\section{Saran}

Berdasarkan hasil penelitian dan pengembangan media pembelajaran berbasis multimedia ini, maka penulis memberikan saran sebagai berikut:

1. Pengembangan lebih optimal sesuai perkembangan zaman diharapkan pada media pembelajaran berbasis multimedia untuk mata kuliah Kompetensi Pembelajaran.

2. Media pembelajaran berbasis multimedia diharapkan dapat dikembangkan lebih lanjut pada tahap validasi uji coba mahasiswa dan penyebaran.

\section{Daftar Pustaka}

Diah, I., \& Nita, S. (2018). Media

Pengembangan Media Pembelajaran... - 29 Gilang 
Pembelajaran Berbasis Multimedia Interaktif untuk Meningkatkan Pemahaman Konsep Mahasiswa. Journal of Computer and Information Technology, 1(2), 68-75.

Diartono, D. A. (2008). Media Pembelajaran Desain Grafis Menggunakan Photoshop Berbasis Multimedia, XIII(2), 155-167.

Erdisna \& Arif Rahman. (2015).

Perancangan Media Pembelajaran Interaktif Berbasis Multimedia Untuk Taman Kanak-Kanak Menggunakan Adobe Flash CS3. Jurnal Kom TekInfo Fakultas Ilmu Komputer, 2(1), 25-33.

Munir. (2012). Multimedia Konsep \& Aplikasi dalam Pendidikan. Bandung: ALFABETA. Retrieved from www.cvalfabeta.com

Realita, K., Rupaidah, E., \& Rizal, Y. (2014). Pengembangan Media Pembelajaran Ekonomi Melalui Multimedia Interaktif Powerpoint Pada Materi Inflas. Pengembangan Media Pembelajaran Ekonomi Melalui Multimedia Interaktif Powerpoint Pada Materi Inflas, (1).

Rezeki, S., \& Ishafit. (2017). Pengembangan Media Pembelajaran Interaktif untuk Sekolah Menengah Atas Kelas XI pada Pokok Bahasan Momentum. JPPPF Jurnal Penelitian \& Pengembangan Pendidikan Fisika, 3(1), 29-34.

Riyana, C., Jenderal, D., Islam, P., Agama, K., \& Indonesia, R. (2012). MEDIA. Jakarta: Direktorat Jendral Pendidikan Islam Kementrian Agama RI.

Sanjaya. (2011). Perencanaan dan Desain Sistem Pembelajaran. Jakarta: Kencana Prenada Media Group.

Suartama, I. K. (2006). Kualitas
Pembelajaran Pada Mata Kuliah Media Pembelajaran. Jurnal Pendidikan Dan Pengajaran, Jilid 43, Nomor 3, 253-262.

Umam, K. (2017). Pengembangan Media Pembelajaran Buku Digital Electronic PUB ( EPUB ) Pada Mata Pelajaran Teknik Mikroprosesor Di SMK. Program Studi Pendidikan Mekatronika: E-Journal Universitas Negeri Yogyakarta, 7(2), 399-409. Retrieved from http://journal.student.uny.ac.id/ojs

Yudiantara, A., Salam, M., \& Ikman. (2015). Pengembangan media pembelajaran interaktif berbasis macromedia flash 8.0 pada materi bangun ruang di smp negeri 9 kendari. Jurnal Penelitian Pendidikan Matematika Volume 3 No. 2 Mei 2015 PENGEMBANGAN, 3(2), 1-16. 